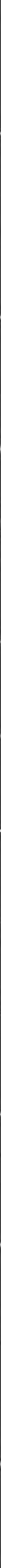





\title{
The Interior of the Earth
}

An Elementary Description

\author{
By Eugene C. Robertson
}

GEOLOGICAL SURVEY CIRCULAR 532 
United States Department of the Interior CECIL D. ANDRUS, Secretary

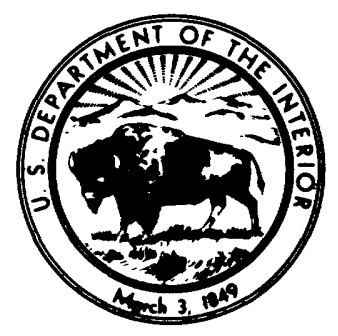

\section{Geological Survey}

H. William Menard, Director

First printing 1966

Second printing 1967

Third printing 1969

Fourth printing 1970

Fifth printing 1972

Sixth printing 1976

Seventh printing 1980 


\section{CONTENTS}

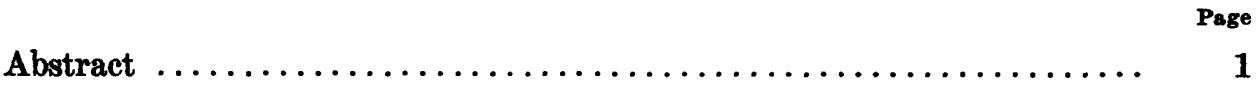

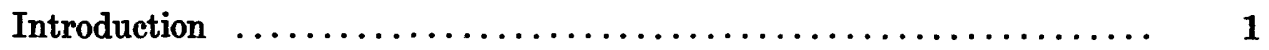

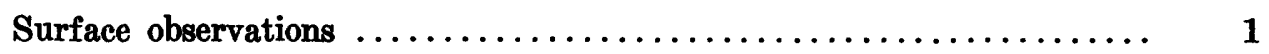

Openings underground in various rocks $\ldots \ldots \ldots \ldots \ldots \ldots \ldots \ldots .2$

Diamond pipes and salt domes $\ldots \ldots \ldots \ldots \ldots \ldots \ldots \ldots \ldots \ldots, 3$

The erast $\ldots \ldots \ldots \ldots \ldots \ldots \ldots \ldots \ldots \ldots \ldots \ldots \ldots \ldots \ldots \ldots, 4$

Earthquakes and the earth's erust $\ldots \ldots \ldots \ldots \ldots \ldots \ldots \ldots \ldots \ldots, 4$

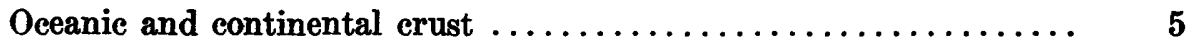

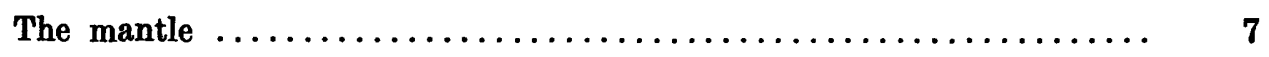

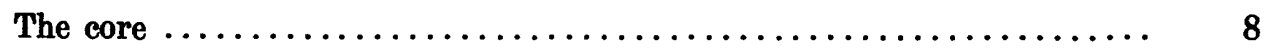

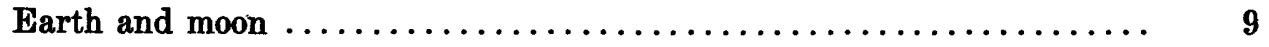

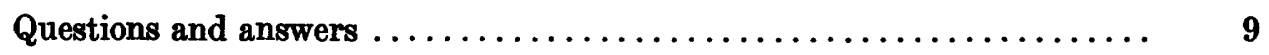

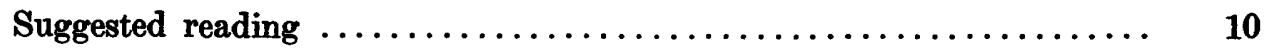

\section{ILLUSTRATIONS}

COVER. The interior of the earth.

Figures 1-6. Sketches of-

1. Man at the edge of a gravel pit ............ 2

2. Gravel pit compared with Bat Cave in Carlsbad Caverns ................... 2

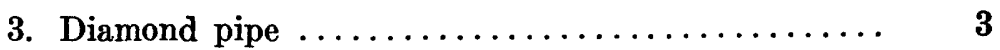

4. Drill hole near salt dome ............... 4

5. Oceanic erust at Hawaii $\ldots \ldots \ldots \ldots \ldots \ldots \ldots \ldots .5$

6. Continental crust under California ........... 6

7. Generalized geologic columns ................ 6

8. Sketch of upper mantle and crust between

Hawaii and California ................. 7

9. Cross section of the whole earth, showing the paths of some earthquake waves $\ldots \ldots \ldots \ldots \ldots \ldots \ldots \quad 8$

10. Graph of earthquake compressional wave velocity and density in the earth $\ldots \ldots \ldots \ldots \ldots \ldots .6$

11. Diagram of earth and moon system $\ldots \ldots \ldots \ldots \ldots \ldots \ldots .9$ 



\title{
THE INTERIOR OF THE EARTH
}

\author{
By Eugene C. Robertson
}

\begin{abstract}
Evidence on the structure and composition of the earth's interior comes from (1) observations of surface rocks, (2) geophysical data from earthquakes, flow of heat from the interior, the magnetic field, and gravity, (3) laboratory experiments on surface rocks and minerals, and (4) comparison of the earth with other planets, the sun, stars, and meteorites.

The major structural components in the earth that are separated by sharp discontinuities are the crust, the mantle, and the core. The crust forms a very thin surface skin, the mantle is a thick shell that extends half the radius down into the earth, and the core occupies the central part. The crust and upper mantle are known to vary in physical and chemical characteristics, both horizontally and vertically; the lower mantle and core are generally assumed to be uniform because their diagnostic geophysical phenomena are masked by the physical-properties of the upper layers.
\end{abstract}

\section{INTRODUCTION}

Idealized, the inside of the earth can be described as being made up of layers, in a sequence of concentric shells as illustrated on the cover. The fact that the earth is not a homogeneous, structureless body has been realized since the time of Isaac Newton, who noted in a discussion of the planets that the average density of the earth is five to six times that of water. The average density of the earth actually is $5.5 \mathrm{~g}$ per $\mathrm{em}^{3}$ (grams per cubic centimeter), and as the average density of surface rocks is only about $2.8 \mathrm{~g}$ per $\mathrm{cm}^{3}$, there must be a large mass of material of higher density inside the earth. We infer from this and other data that there is a heavy central part in the earth. In fact, during the last 60 years, geophysicists and geologists have estimated with increasing confidence the thickness and character of each of the successive layers in the earth, including variations within some layers.
Man has actually looked into the earth in deep mines and drill holes only a very small distanceabout 5 miles of the 4,000-mile distance to the earth's center. Furthermore, man will likely never be able to make a hole into the deep interior, so what we learn about the interior has to be from indirect evidence. At present, this evidence consists of (1) direct observation of rocks at the surface, (2) secondary observations based on geophysical phenomena (including waves through the earth from earthquakes and explosive sources, planetary motions of the earth, flow of heat from the interior, the magnetic field, and gravitational attraction), (3) laboratory experiments on surface rocks and minerals, and (4) comparison of the earth with the other planets, the sun, stars, and meteorites, which may be fragments of a disintegrated former planet. Our present understanding of the structural features and the composition of the earth is obtained from all these sources.

In the following discussion of the interior of the earth, we will use facts from these sources to consider layering, the existence of openings, and the physical state and composition of the rocks and minerals presumed to occur in the earth. Our estimates of composition are not much better than conjectures at present, but they are reasonably consistent with geophysical observations.

\section{SURFACE OBSERVATIONS}

Let us start from the earth's surface with features that we know and progress deeper and deeper inside the earth, using a series of scaled illustrations to comprehend better the sizes of structures in the earth. First, we look at the rocks under foot at a familiar scale and then at diagram- 

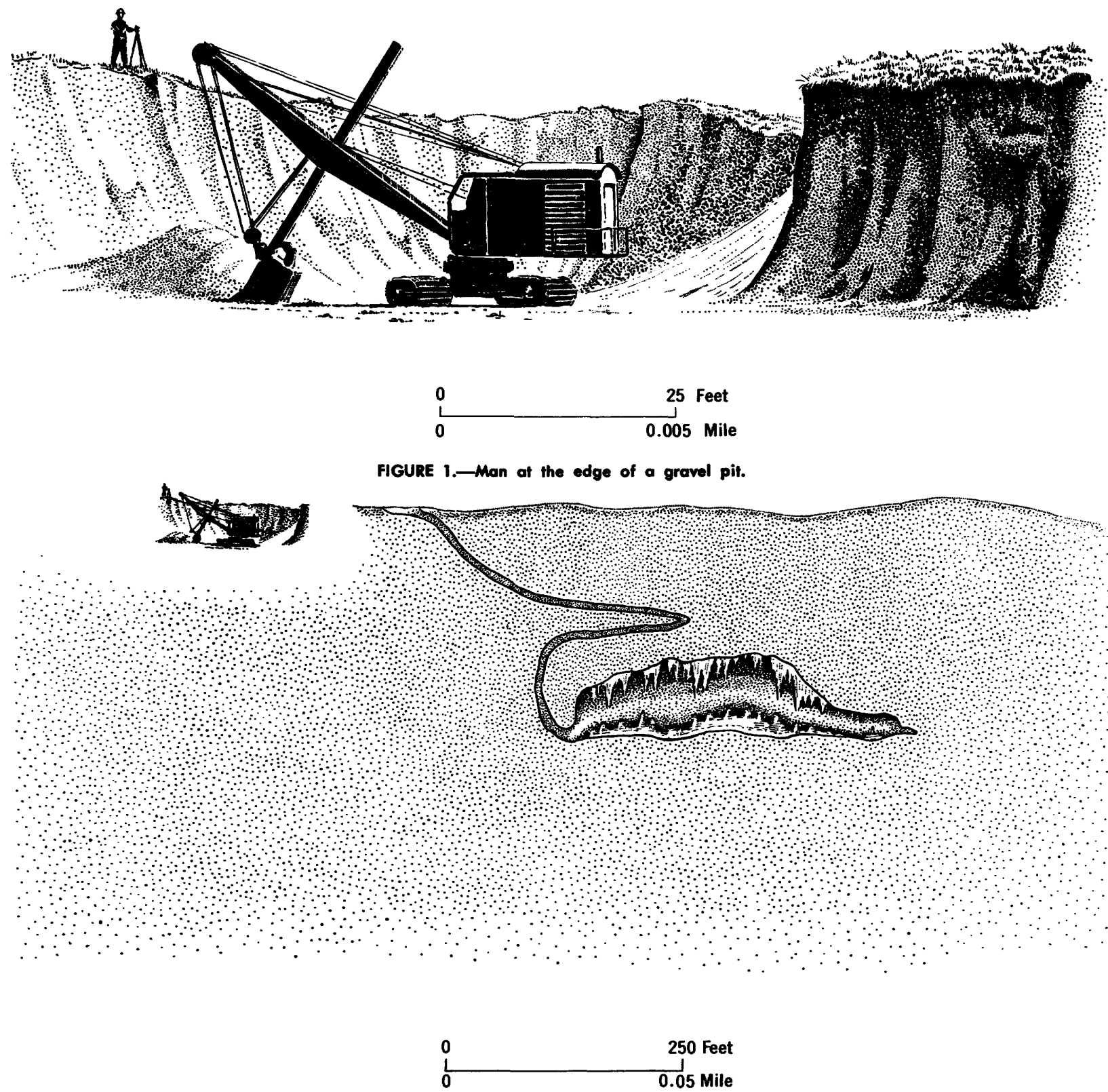

FIGURE 2.-Gravel pit compared with Bat Cave in Carlsbad Caverns. Contiguous caves-not shown-are found to 1,100 feet below the surface; the Big Room at an 830-foot depth is half a mile long and over 250 feet high.

matic cross sections of the earth; each structural feature is reduced in size 10 times from one drawing to the next and compared with a new feature : 1 inch in the first figure will equal 10 million inches in the last. In all drawings, the vertical scale is equal to the horizontal scale, with no vertical exaggeration.

In the first drawing, figure 1 , let us compare the length of a man's legs, about $21 / 2$ feet, with the depth of a gravel pit, about 25 feet; one length is 10 times the other. In figure 2 the gravel pit and steam shovel are shown reduced 10 times in size from figure 1, and a room in Carlsbad Caverns in New Mexico is sketched at this new, 10-timessmaller scale.

\section{Openings Underground in Various Rocks}

The existence of such large rooms as in the Carlsbad Caverns brings up the question of how large an opening at a given place underground can be supported by the surrounding rock. Sand and gravel like that shown in the pit in figure 1 
are too loose and unconsolidated to support a very large hole, and this is true of the mud or sand deposited as sediment at the bottom of a sea, lake, or river. However, mud or sand buried beneath the earth's surface by a thick deposit of similar material may be consolidated by pressure, heat, and chemical action into a sedimentary rock such as shale, sandstone, or limestone which would support a large opening.

At the relatively shallow depth of a thousand feet, huge natural caves, hundreds of feet in extent, larger than the one illustrated in figure 2, can be dissolved out of limestone by percolating ground water, and they will stand open because most limestone is strong. The weight of the rock above is not great enough to collapse the caves. On the other hand, less strong sedimentary rocks, such as shale or poorly cemented sandstone, would not support smaller openings (say, $40 \mathrm{ft}$ across) under a load of a thousand feet of overlying rock.

Just as in limestone caves, large openings at a 1,000-foot depth can also stand in unfractured igneous rocks, which are composed of hard silicate minerals and which were emplaced in a molten state and then cooled to form strong, massive bodies. Similar openings can stand in unfractured metamorphic rocks, which are sedimentary or igneous rocks that have been very highly compressed and heated and which are now also strong and solid. Igneous or metamorphic rock can support openings even at 1-mile depth, as in mine workings; however, in very deep mines like the South African gold mines at 2 miles down, spalling of the walls and cave-ins can cause serious problems.

Immense chambers are sometimes postulated to exist very deep in the earth, but actually a 10-foot opening would not stand unsupported even in the strongest rock at a depth of 10 miles or more. The pressure at 10 miles exceeds the strength of the rock for a 10-foot span, and so it is merely speculation to predict larger openings at greater depths.

\section{Diamond Pipes and Salt Domes}

The underground diamond mines of South Africa and Siberia do not extend to as great a depth as the gold mines, but the diamond "pipes" themselves (fig. 3), in which the mining is done, extend as tubular conduits (hence the name "pipe") deep into the earth. This geologic feature is funnel shaped, decreasing in diameter to a narrow neck at a depth of a few thousand feet. We know that the neck extends beneath the surface about 100 miles because laboratory experiments show that high pressure and temperature, such as would be found

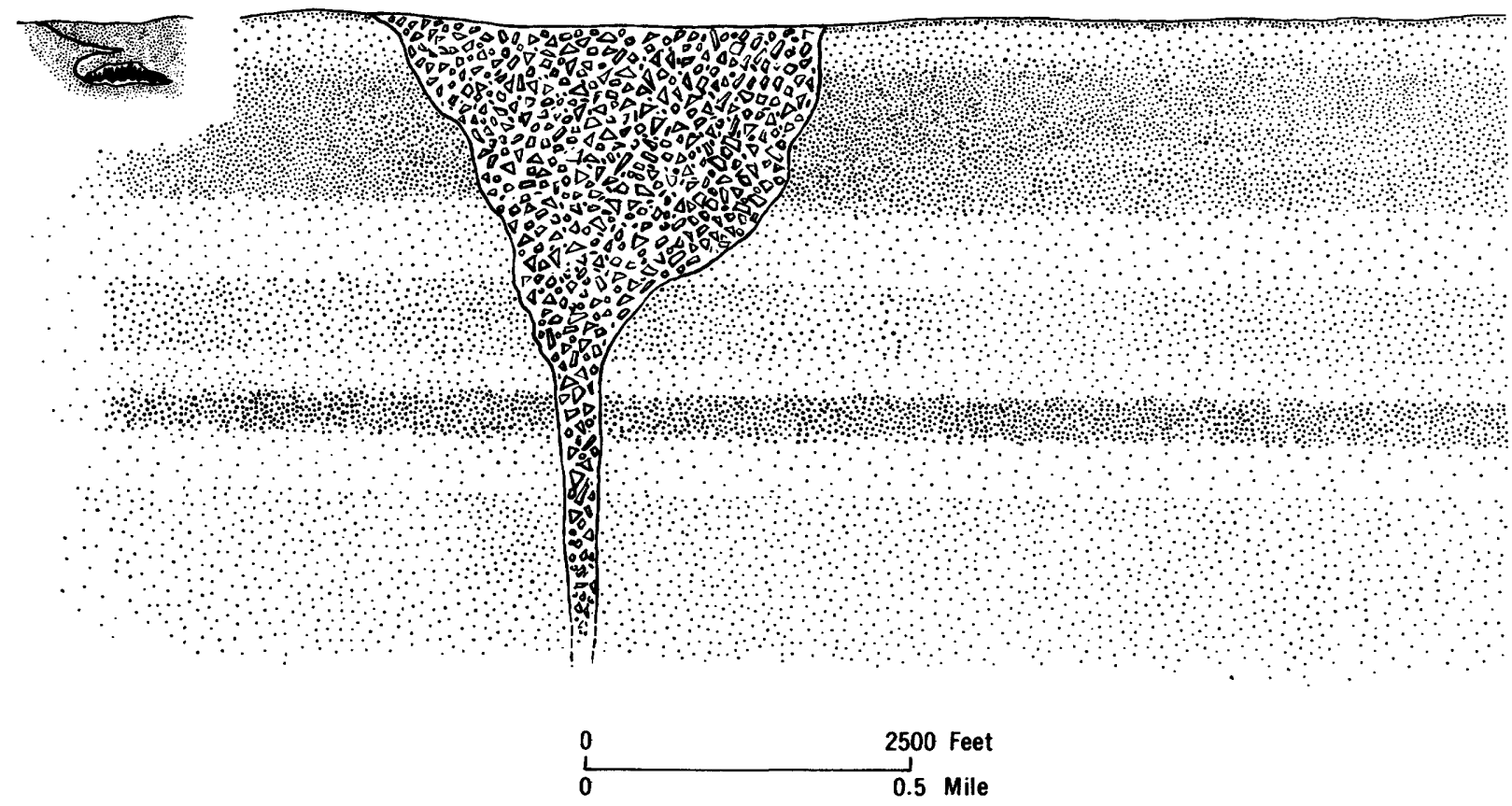

FIGURE 3.-Diamond pipe, like the Kimberley in South Africa, compared with Bat Cave, Carlsbad Caverns, N. Mex. 

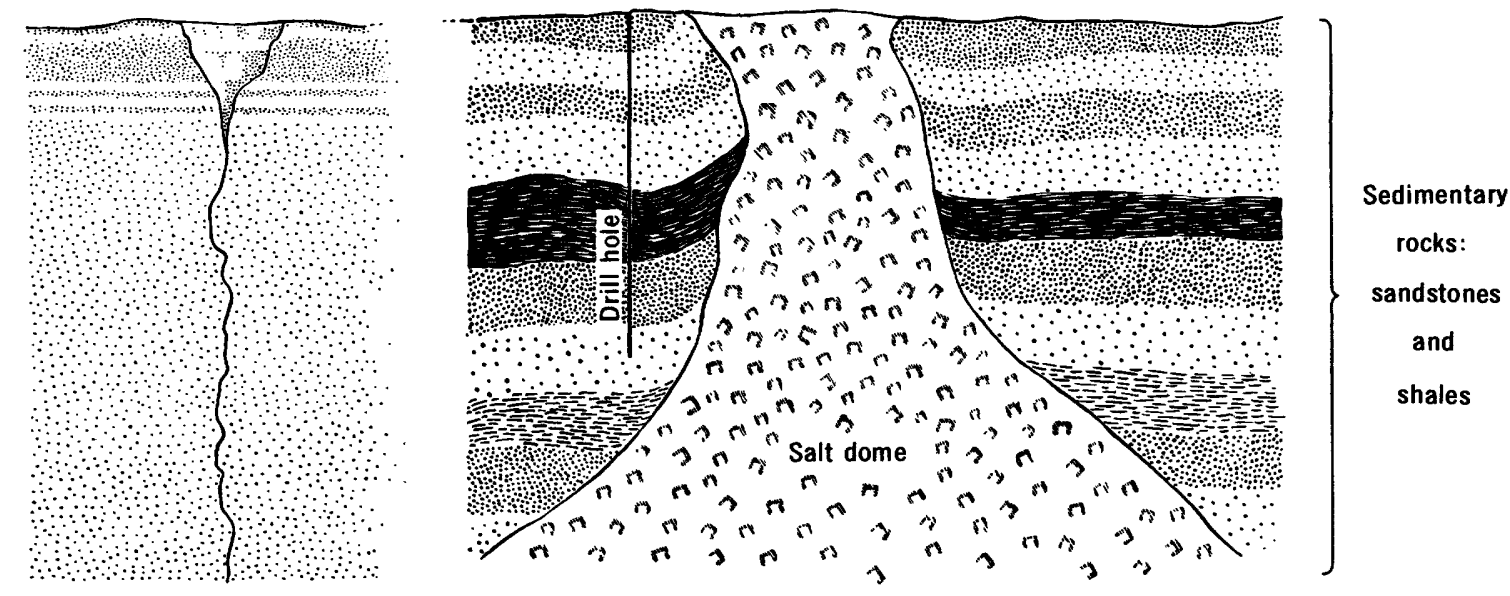

5 miles

FIGURE 4.-Drill hole, 25,000 feet deep, near a salt dome, like the domes found in Texas, Louisiana, Mississippi, and the Gulf of Mexico.

in the earth at such a depth, are required to form diamonds. Disseminated through the rock in the pipe are not only the sparse diamonds (about 1 carat per ton), but also sporadic inclusions of eclogite and peridotite, the two dark-colored dense igneous rocks which we think make up the outer mantle of the earth. The mantle and its constituents are discussed below.

In the next drawing (fig. 4), at a scale 10 times smaller than the previous figure, we compare the diamond pipe with a salt dome, which has an upside-down funnel shape and is filled with salt. An adjacent drill hole is sketched in figure 4 because oil-well holes, as much as 5 miles deep, are commonly drilled near salt domes to tap the oil found in porous sandstones in the upturned beds around the domes, as for example, in the deep basin of sedimentary rock near the Gulf of Mexico.

A salt dome is presumed to form because the weight of 1 to 8 miles of rock on the thick horizontal parent salt bed causes the lower density relatively plastic salt to force its way upward through a crack in the rocks, sometimes to the surface. The intruding salt enlarges the crack and turns up the adjacent sedimentary beds. The salt rises until the thickness and strength of the overlying rock prevent further movement.

At depths of 5 to 10 miles only small openings (perhaps 0.1 in.) can stand in unconsolidated sedimentary rocks, such as those in the Gulf of Mexico basin, and only slightly bigger openings (perhaps 1 in.) can persist in massive hard rocks.

\section{THE CRUST}

\section{Earthquakes and the Earth's Crust}

When we remember that a great thickness of sedimentary rocks was uplifted 6 miles above sea level to form the Himalaya Mountains, we are made aware that tremendous forces are available inside the earth to move its surface up and down and laterally. We presume that local sources of heat deep inside the earth provide the energy to build mountains and to lower basins. The surface expressions of the release of mechanical energy of mountain building and other earth movements are earthquakes.

Geologists, in mapping the rocks at the earth's surface, locate the faults (fractures) and folds (plastic bends) which are evidence of the mechanical deformation of rocks in mountain building. Sudden displacement of rocks on either side of a fault produces a shaking of the earth called an earthquake; earth tremors are also produced by motion of the motten rock under volcanoes. The association of faults with earthquakes is a matter of historical record for the San Andreas fault along the coast of California and for faults in Chile, in Turkey, and elsewhere.

The violent breaking of the rock at a fault sets up vibrations, and waves of motion propagate through the whole earth, much like the waves produced in a pond when a stone is dropped into it. 


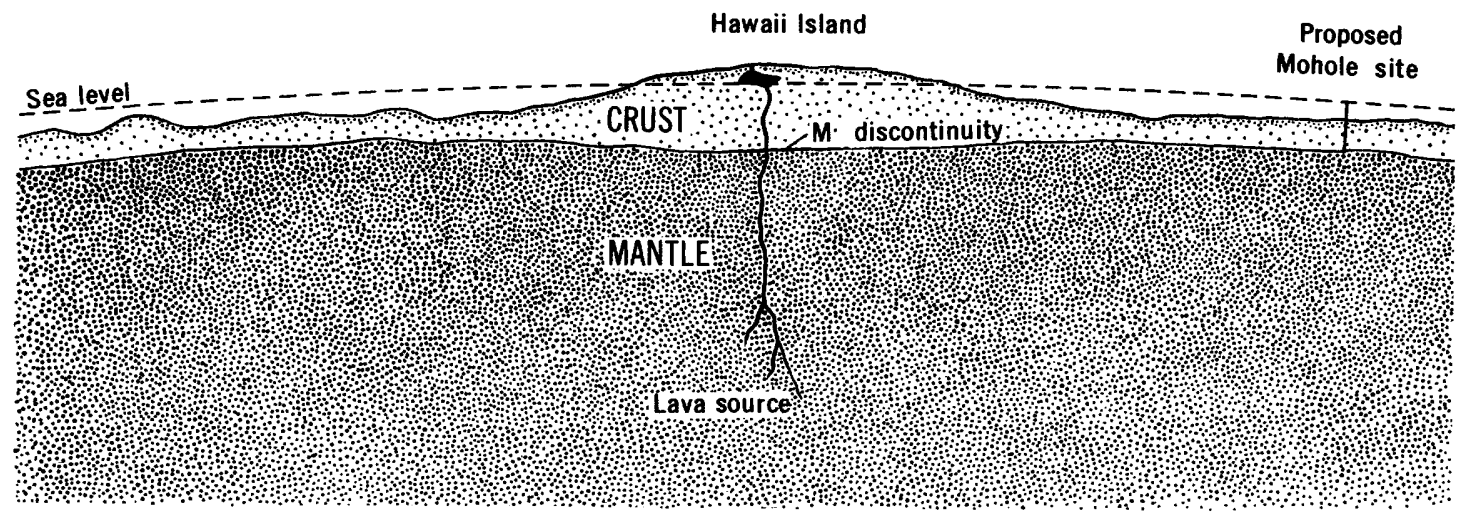

50 Miles

FIGURE 5.-Oceanic crust at Hawaii Island. The proposed site of the 34,000-foot Mohole is 150 miles north of Hawaii olthough shown closer in the figure.

Earthquake waves transmitted through the earth are of two types: (1) compressional waves, $P$, in which motion of solid particles is back and forth, parallel to the direction of travel, and (2) shear waves, $S$, in which particle motion is across, transverse to the direction of travel.

Geophysicists study the velocity and the paths of earthquake waves to learn about the earth's interior. One of them, a Yugoslav named Mohorovičić (pronounced Mo-ho-ro-veé-chich), in 1909 discovered a discontinuity between what we now call the crust and the mantle by observing a sharp increase in velocity of earthquake waves going from crust to mantle. The discontinuity has been named after him; it is sometimes called the $M$ discontinuity, or more colloquially the "Moho"; a hole proposed to be drilled through the discontinuity has been dubbed the "Mohole."

\section{Oceanic and Continental Crust}

The crust of the earth ranges in thickness from about 5 miles at some places under the oceans to about 30 miles under high mountains; it forms a thin skin around the earth as shown on the cover. Below is the thick shell of the mantle. Oceanie and continental crustal thicknesses and topography are shown in the cross sections of figures 5 and 6 , plotted at a scale that is 10 times smaller than the previous figure. In these figures in which the ver- tical and horizontal scales are equal, the eraggy slopes of Mount Whitney in California and of Mauna Loa on Hawaii Island are not so impressive when compared with the thickness and the lateral extent of the earth's crust below. Relatively great thicknesses of crust, like the 34-mile thickness under the Sierra Nevada, are common under mountain ranges and are very much more than the 4-mile thickness of crust (covered by $21 / 2$ miles of water) at the Mohole site.

We believe that the continental crust is largely made up of (1) dense light-colored igneous rocks, such as granite or quartz diorite, in the upper part and (2) basalt, a dark and slightly denser igneous rock (commonly erupted from volcanoes), in the lower part. The oceanic crust appears to be composed almost entirely of basalt. The relative "thicknesses of the probable rocks occurring in four representative oceanic and continental locations (figs. 5 and 6) are given in figure 7 . Notice that the composition of the crust as well as its thickness varies laterally; the crust is not just a homogeneous, flat layer.

The acclaimed purpose for drilling the Mohole is to get a sample of rock from the mantle. It is widely believed that the discontinuity in earthquake wave velocity at the Moho is due to a change of rock type, from basalt in the lower part of the crust to the more dense eclogite or peridotite in the mantle. From the deep-sea sediments, from other crustal rocks, and from the mantle rock obtained 

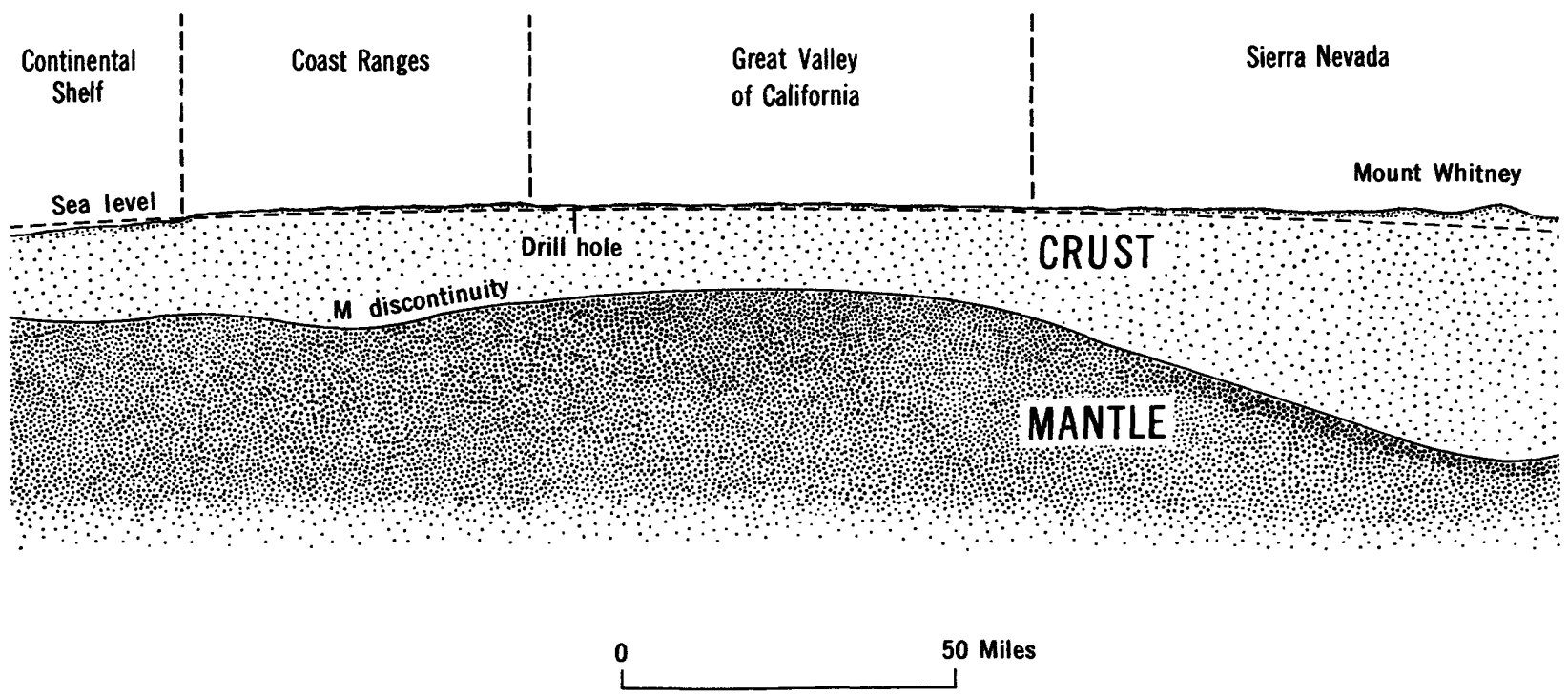

FIGURE 6.-Continental crust under California, showing a 21,500-foot drill hole for comparison with drill holes in figures 4 and 5.
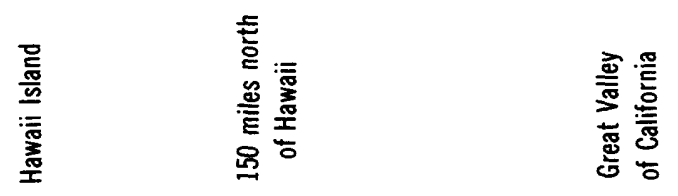

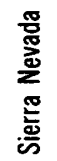

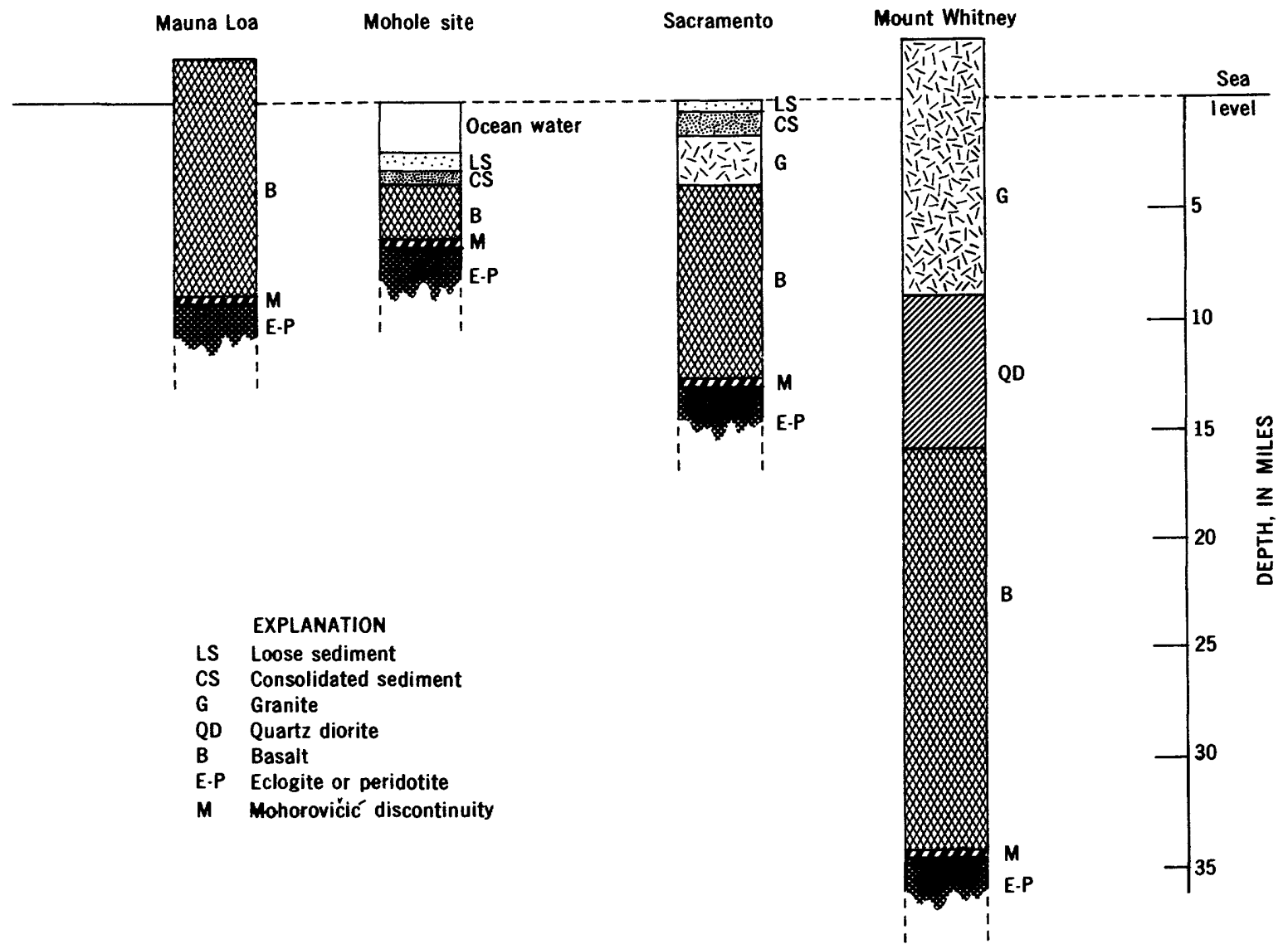

FIGURE 7.-Generalized geologic columns, showing rock types at two places each in figures 5 and 6. 


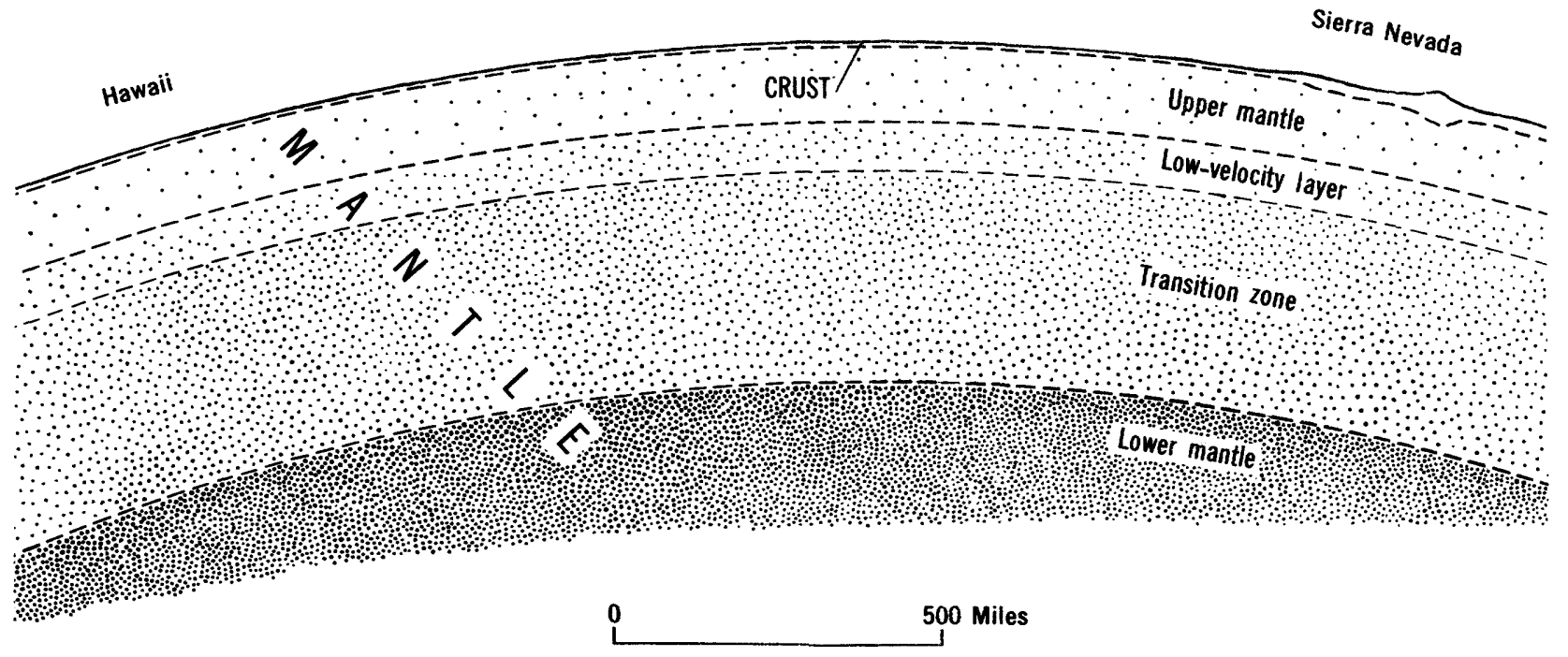

FIGURE 8.- Upper mantle and crust between Hawaii and California. The crust is very thin relative to the rest of the earth.

from the Mohole, we will learn about the origin and history of life, of the oceans, and of the earth itself.

\section{THE MANTLE}

Earthquake wave velocities are faster in the upper mantle than in the crust, but the velocities decrease a little at a depth of about 100 miles in what is called the low-velocity layer (fig. 8). Although it is shown with constant thickness in the cover drawing and in figures 8 and 9, the lowvelocity layer may not extend uniformly around the earth; there is conflicting evidence for its existence under the central parts of the continents and oceans. In fact, it may be restricted to the mountainous regions, especially along continental margins, where volcanic activity and earthquakes occur. Considering the probable rise of temperature with depth in the earth, it is feasible for the temperature of the rock in this layer to be near the melting point; this would explain the reduction in the wave velocities and would provide a source for the lava erupted from volcanoes or extruded in diamond pipes.

Below, in the transition zone, the earthquake wave velocities increase markedly again. They taper off as the zone grades into the lower mantle but continue to rise gradually to a maximum at the core boundary. (See fig. 10.) The boundaries of these layers in the mantle are gradational; and although their depths are widely accepted, the details of their composition and structure are not known.

The possible openings in the mantle must be very small. We know from the occurrence of deepfocus earthquakes (as deep as 450 miles) that stresses may build up almost to the bottom of the transition zone, and this indicates that the rock there may have some strength. However, it is not likely that openings larger than 0.01 inch could stand in the low-velocity layer, owing to the weakness of rock near its melting point, or cauld stand in the transition zone or lower mantle, owing to the very high pressure in relation to rock strength.

The composition of the mantle has been conjectured from studies of volcanic lava, diamond pipes, and meteorites and from experiments on minerals and rocks. These studies indicate that the upper few hundred miles may be composed of eclogite and peridotite, which are composed mostly of iron and magnesium silicate minerals and some complex calcium, sodium, and aluminum silicate minerals. In the transition zone, denser forms of these minerals are presumed to exist. In the lower mantle, because of the very high pressure, only the simple oxides of iron, magnesium, and silicon are thought to be present. We are far from being sure of the composition of the mantle, which undoubtedly varies laterally as well as vertically. 


\section{THE CORE}

Below the mantle is the earth's core, discovered by $R$. D. Oldham in 1906 from a study of earthquake records. The core itself is divided into an outer part and an inner part, as shown at a 10 times further reduced scale in figure 9 . The outer

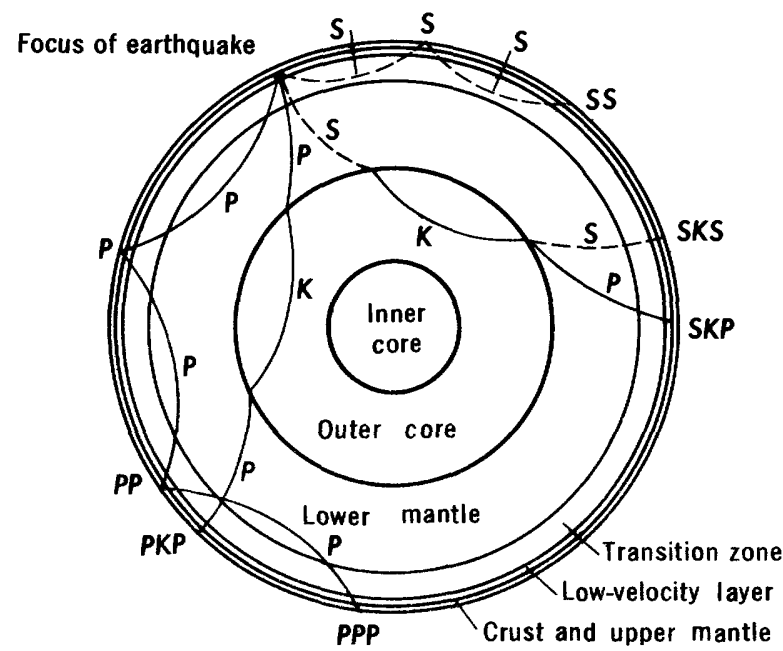

0 5000 Miles

FIGURE 9.-Cross seciion of the whole earth, showing the paths of some eart'squake waves. Compressional waves ( $P$, solid lines) are refracted sha-zly by the core, as shown by the PKP trajectory. Shear waves ( $S$, dashed lines), as such, end at the core, although they may be converted to $P$ waves, traverse the core as a compressional wave $(K)$, and emerge in the mantle again as $P$ and $S$ waves, that is, SKP and SKS. The waves may be reflected back into the earth at the surface and be picked up further on, as in trajectories PP, PPP, and SS. core is presumed to be liquid because it does not transmit shear waves $(S)$, and because it sharply reduces the velocity of compressional waves $(\boldsymbol{P})$. (The $P$, and $S$ waves are the two earthquake waves that go through the earth.) The inner core, discovered by its higher $P$-wave velocity in 1936 by Miss I. Lehmann, is considered to be solid. In figure 9 the core looks about as big as the mantle, but actually the core occupies only 15 percent of the earth's volume, whereas the mantle occupies 84 percent. The crust occupies the remaining 1 percent.

As shown in figure 9, the ray paths of earthquake waves from the focus, where the fault displacement or other disturbance initiates the earthquake, are curved in passing through the earth; the curvature is a refraction due to the increase in velocity with depth. Earthquake records, called seismograms, require great care in interpretation to disentangle the various waves; many more wave paths are observed than are shown in figure 9.

At the outer boundary of the core, there is a sharp discontinuity in both the $P$-wave velocity and the density, as shown in figure 10. These very striking changes in properties occur in a narrow border zone between the mantle and core, perhaps less than $\mathbf{1 0}$ miles thick. It is certain that there is a marked compositional difference between the mantle and core.

P-WAVE VELOCITY, IN KILOMETERS PER SECOND

DENSITY, IN GRAMS PER CUBIC CENTIMETER

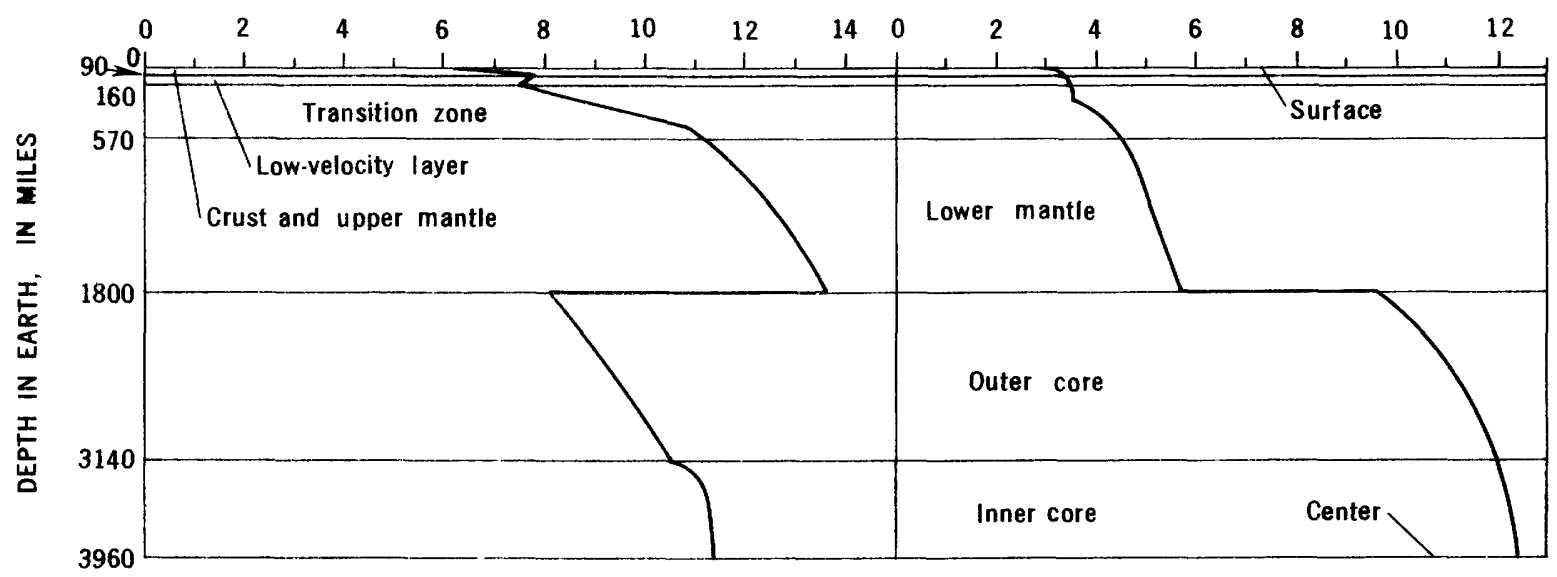

FIGURE 10.-Variation of earthquake P-wave velocity and of density with depth in the earth, illustrating the shart decrease in $P$ in the low-velocity layer and the sharp rise in $P$ in the transition zone, as well as the abrupt changes in $P$ and in density af the core-manfle: boundary. 
By analyzing seismograms for the variation of $\boldsymbol{P}$ and $S$ wave velocities with depth and for the free oscillations of the earth, by observing the planetary motions of the earth, and by knowing the earth's average density $\left(5.5 \mathrm{~g}\right.$ per $\left.\mathrm{cm}^{3}\right)$, the density of the core has been determined to be about $\mathbf{1 1}$ $\mathrm{g}$ per $\mathrm{cm}^{3}$. Iron is the most likely constituent of the core for the following reasons: Iron has about the right density; it has the right $\boldsymbol{P}$-wave velocity; its abundance in the earth would be about the same as in the sun and stars; it occurs in large proportions in meteorites, which are presumed to be fragments of a disintegrated planet, analogous to the earth; it would be properly molten at the core temperature and pressure $\left(8,000^{\circ} \mathrm{F}\right.$ and 3 million atmospheres); and even though molten, iron is a satisfactory material to account for the earth's magnetic field. The inner core is probably pure iron.

\section{EARTH AND MOON}

A view of the earth and moon at about average separation is shown in figure 11, drawn at the final, smallest scale; the size of the moon here is about equal to the size of the man's head in figure 1 , although the moon is actually 10 million times greater in diameter. The diameter of the moon is just half that of the earth's core and one-fourth that of the whole earth. When next you look at the moon, these proportions will enable you to visualize the size of the earth's core and of the earth itself at a distance of 240,000 miles.

Judging from the moon's average density ( $3.3 \mathrm{~g}$ per $\mathrm{cm}^{3}$ ), we can hypothesize that its composition is much like the earth's crust and upper mantle. Recent data from American and Soviet satellites show that the moon's magnetic field is very small, which indicates that there is only a small amount of iron in the moon; furthermore, the iron is probably dispersed and not in a central core, a conclusion based on the motions of the moon. Samples of the moon's surface brought back by astronauts will not only give us a first estimate of the composition of the moon but may also tell us something about the origin of the solar system and about the interior of the earth as well.

\section{QUESTIONS AND ANSWERS}

Geologists, geochemists, and geophysicists have contributed to our understanding of the earth's

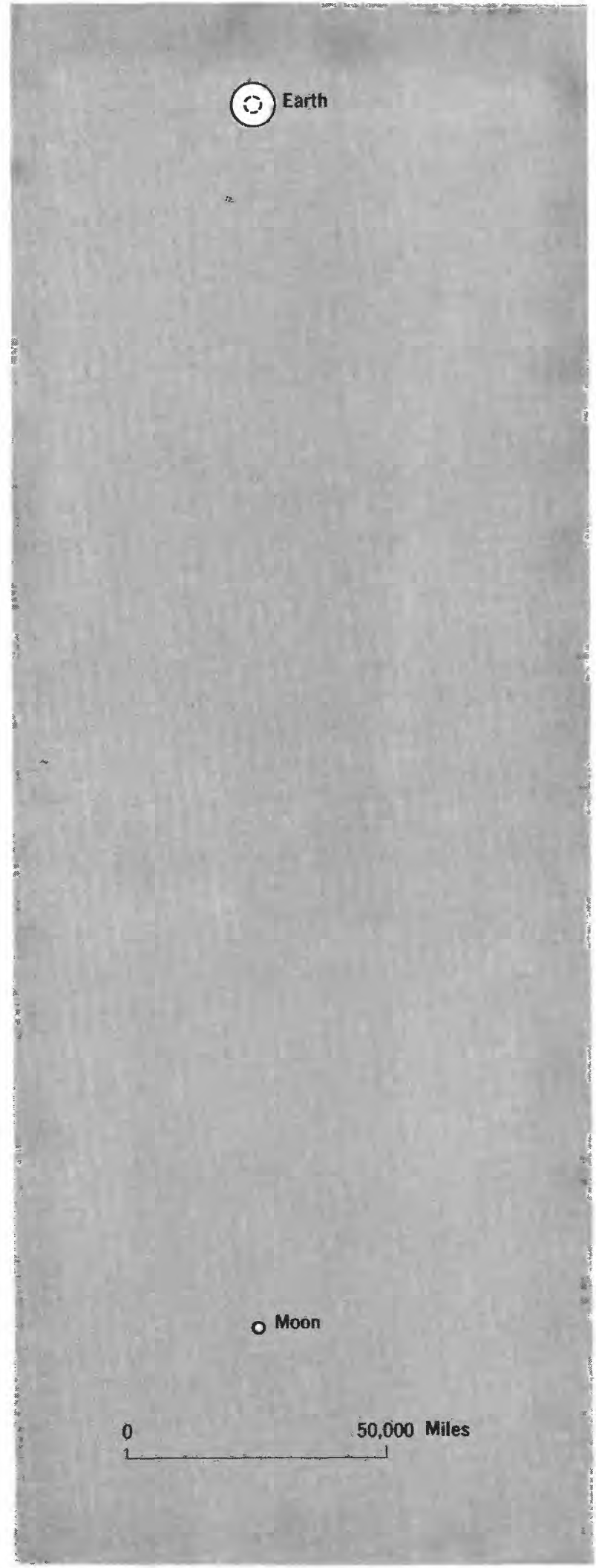

FIGURE 11.-Earth and moon system, showing the earth's core for comparison. 
internal structure and composition, but questions about the earth's interior are still very much more numerous than answers: What are the causes and mechanisms of earthquakes, mountain building, and subsidence of large basins? What is the energy source for these phenomena? Why do volcanoes erupt, and what is their source? How do large granite bodies melt and move into place? How old is the earth? What have the structure and composition of the earth and its temperature and magnetism been like throughout geologic time? Why is the crust thinner under the oceans than under the continents?

Geological Survey scientists are actively searching for answers by measuring the velocities of earthquake waves in the mantle and crust, by ascertaining the variation of temperature with depth and the amount of heat flowing from the earth's interior, by determining the positions of the earth's magnetic poles millions of years ago as recorded in the rocks and compared with the present magnetic field, and by estimating the thickness of the crust under mountains and plains from the gravitational attraction. Survey geologists observe the occurrence and character of volcanic rocks to learn about the chemical processes of the mantle and crust, and they map the folds and faults in rocks-the external effects, demonstrated by every earthquake, of the mechanical forces deep in the earth. In Survey laboratories geophysicists and geochemists study the properties and composition of rocks and minerals under high pressure and temperature, simulating the conditions inside the earth. The interior of the earth is a fascinating topic for further study.

Earth layers on layers Up quaking, round ringing Deep secrets revealing To us unawares.

Anon. (ca. 1965)

\section{SUGGESTED READING}

Hurley, P. M., 1959, How old is the earth $1:$ Garden City, N.Y., Doubleday and Co., Inc., 160 p.

Jacohs, J. A., 1963, The earth's core and geomagnetism: New York, Macmillan Co., 137 p.

Scientific American, 1957, The planet earth: New York, Simon and Schuster, Inc., $168 \mathrm{p}$.

White, J. F., ed., 1962, Study of the earth: Englewood Cliffs, N.J., Prentice-Hall Internat., Inc., 408 p. 